\title{
Direct Condensation Reaction for Grafting of Polyethylene Glycol Monomethyl Ether on Poly(Methacrylic Acid-co-Methyl Methacrylate) for Application in Biomedical Engineering
}

\author{
A. Negahi Shirazi ${ }^{1}$, M. Imani ${ }^{2, *}$, S. Sharifi ${ }^{2}$ \\ ${ }^{1}$ Biomedical Engineering Department, Amirkabir University of Technology, Tehran, 15875/4413, Iran \\ ${ }^{2}$ Novel Drug Delivery Systems Department, Iran Polymer and Petrochemical Institute, Tehran, 14965/115, Iran
}

\begin{abstract}
Synthesis, characterization and cytotoxicity evaluation of copolymers based on polyethylene glycol monmethyl ether-g-poly(methacrylic acid-co-methyl methacrylate) are reported via a polymeric precursor method. Grafting was accomplished based on direct condensation reaction in the presence of dicyclohexylcarbodiimide as an esterification-promoting agent catalyzed by dimethylamino pyridine. Polyethylene glycol grafted copolymers were characterized using various spectroscopic techniques; in addition, their biocompatibility was studied. Manifestation of bands assigned to the ester functional groups in Fourier transform infrared spectra and nuclear magnetic resonance was employed for structural characterization of the grafted copolymers. Performance of grafting reaction was guaranteed by determination of grafting efficacy. Cytotoxicity evaluations of the grafted copolymer using L929 fibroblast cell line elucidated acceptable biocompatibility profile; consequently, the applicability of the copolymers is confirmed for biomedical applications.
\end{abstract}

Keywords Graft Copolymers, Esterification, Biocompatibility, Biological Applications of Polymers, Polycondenstion

\section{Introduction}

Development of new, engineered materials with desired properties (e.g. mechanical[1], thermal[2] or biological[3-6]) for specific applications have been recognized as a very promising field in material sciences. More specifically, the polymeric materials are very attractive due to their multifarious possible variations in the nature (or ratio) of the initial monomer(s), synthesis method, catalysts, final processing etc. to provide new materials with specific properties[1-9].

In this regard, two major categories of physical and/or chemical approaches are being adopted in modification of polymers, which are planned to be employed in biomedical applications. For instance, plasma surface modification of polyamide 6 is frequently reported to increase its wettability[10-14] or to improve cell adhesion and proliferation on $\operatorname{poly}(L$-lactide $)$ and $\operatorname{poly}(D, L$-lactide-co-glycolide)[15]. Chemical treatment of biomaterials consists of various methods for both grafting[16-18] and crosslinking[19-21], together with the structural modifications such as hydro-

* Corresponding author:

M.Imani@ippi.ac.ir (M. Imani)

Published online at http://journal.sapub.org/ajbe

Copyright (C) 2011 Scientific \& Academic Publishing. All Rights Reserved genation[22], halogenation[23], and hydrohalogenation[24, 25] which are widely described in the literature.

According to its desirable and intrigue properties including biocompatibility, bioresorbability (up to $20 \mathrm{kDa}$ nominal molecular weight), ionic conductivity, wettability and resistance to protein adsorption, polyethylene glycol (PEG) [26] has been found as an outstanding modificatory potency for biological entities, polymers and surfaces[26-30]. For instance, modification of acrylic resins using PEG has attracted much attention[29-42]. Generally, these amphiphilic PEG-grafted copolymers were prepared by either (co)polymerization of vinyl-derivatives of PEG[32-36] or synthesis of acrylic polymeric precursors followed by PEG conjugation via polymeric analogous reactions[37-42]. A procedure using polymeric precursors was adopted by Chiu et al.[37] in order to prepare a polymeric drug carrier via synthesis of a linear acrylic resin from methyl acrylate, stearyl methacrylate, acrylic acid and PEG acrylate and subsequent reaction with monomethoxy polyethylene glycol (mPEG) in different molar ratios of the reactants and mPEG nominal molecular weights. Synthesis and characterization of a variety of PEG-grafted copolymers upon polymeric precursors method was reported consecutively in the last decade of ex-century[38-42], however, there are several uncovered aspects in the mentioned researches including direct esterification of carboxyl and hydroxyl functional 
groups of polyacids and $\mathrm{mPEG}$ that should be defined. In addition, the biocompatibility and cell supporting capacity of these copolymers should be enhanced.

The aim of the present work is grafting of mPEG on poly(methacrylic acid-co-methyl methacrylate) (MA-coMMA) via a polymeric precursor method. This method is based on the adoption of a direct condensation reaction in the presence of dicyclohexylcarbodiimide (DCC), which was used as an esterification-promoting agent catalyzed by dimethylamino pyridine (DMAP). PEG-grafted copolymers were characterized by Fourier transform infrared spectroscopy (FTIR) and proton nuclear magnetic resonance spectroscopy $\left({ }^{1}\right.$ HNMR) techniques. Grafting efficiency and their biocompatibility was also evaluated. To our knowledge, synthesis of this specific material has not been reported yet.

\section{Materials and Methods}

\subsection{Materials}

Poly(methacrylic acid-co-methyl methacrylate) (MA-coMMA, Mw=135000 g.mol ${ }^{-1}$ ) was supplied by Röhm Pharma $\mathrm{GmbH}$ (Darmstadt, Germany) and dried by leaving in a forced-air convection oven at $110^{\circ} \mathrm{C}$ for 24 hrs before use. Monomethoxy polyethylene glycol (mPEG, of $350 \& 750$ g.mole ${ }^{-1}$ nominal molecular weights) were supplied by Fluka (Ronkonkoma, USA) and dried using azeotropic distillation in toluene. N,N'-Dicyclohexylcarbodiimide (DCC) and 4(dimethylamino) pyridine (DMAP) were purchased from Merck Chemicals (Darmstadt, Germany) and used without further purification. Acetone (Merck Chemicals Co., Darmstadt, Germany) was purified by distillation in ambient pressure before heating under reflux condition with successive quantities of potassium permanganate. It was then dried using anhydrous potassium carbonate, filtered from the desiccant and stored over type $4 \AA$ molecular sieves. Toluene and other solvents and reagents were all of analytical grade and purchased from Merck and used as received.

Acid value of MA-co-MMA copolymer was determined according to the United States Pharmacopoeia[43]. Briefly, a precise weight of copolymer was dissolved in acetone $(1 \%$ $\mathrm{w} / \mathrm{v})$ then titrated with $\mathrm{NaOH}$ solution $(0.1 \mathrm{~N})$ in the presence of phenolphthalein until its color changing was remained constant for at least 15 seconds. According to the procedure[43] each $\mathrm{mL}$ of the used titrant is equal to $8.609 \mathrm{mg}$ of methacrylic acid hence, methacrylic acid percentage in the backbone can be determined using the following equation:

$$
\text { Methacrylic Acid }(\%)=\frac{N a O H(m L) \times 8.069}{M A-c o-M M A(m g)} \times 100
$$

\subsection{Grafting Reaction}

In a typical procedure, 0.0163 mole of pre-purified and dried MA-co-MMA copolymer was dissolved in $100 \mathrm{~mL}$ of neutralized acetone and charged into a $250 \mathrm{~mL}$ three-necked reaction flask equipped with a reflux condenser, dropping funnel and thermometer. DMAP $(0.1 \% \mathrm{~mol} / \mathrm{mol}$ to $\mathrm{mPEG})$ was added to the mixture and heated to $45^{\circ} \mathrm{C}$ under reflux condition. A respective amount of $\mathrm{mPEG}$ was dissolved in $50 \mathrm{~mL}$ of acetone to yield 10,20 or $30 \%$ molar ratio to methacrylic acid units. DCC (1\% mol/mol to $\mathrm{mPEG})$ was dissolved in the mPEG solution at room temperature. This solution was added dropwise to the reaction flask in the period of 15 minutes. The precise compositions used in the synthesis of grafted polymers are tabulated in Table 1. In the samples' nomenclature the molar ratio of $\mathrm{mPEG}$ to methacrylic acid units and nominal molecular weights of mPEG were described by the first and second numbers, respectively.

Table 1. Feed Ratio Composition for Reactants Used in the Synthesis of Grafted Copolymers (MA-co-MMA amount was set at 16.3 mmole)

\begin{tabular}{|c|c|c|c|c|}
\hline \multirow{2}{*}{$\begin{array}{c}\text { Sample } \\
\text { Code }\end{array}$} & \multicolumn{2}{|c|}{ mPEG } & \multirow{2}{*}{$\begin{array}{c}\text { DCC } \\
\text { (mole) }\end{array}$} & $\begin{array}{c}\text { DMAP } \\
\text { (mole) }\end{array}$ \\
\cline { 2 - 3 } & $\begin{array}{c}\mathrm{M}_{\mathrm{n}} \\
\text { (g.mole-1) }\end{array}$ & Mole & & \\
\hline $10 \mathrm{P} 350$ & 350 & 0.0016 & 0.0016 & 0.0001 \\
\hline $20 \mathrm{P} 350$ & 350 & 0.0033 & 0.0033 & 0.0003 \\
\hline $30 \mathrm{P} 350$ & 350 & 0.0049 & 0.0049 & 0.0005 \\
\hline $10 \mathrm{P} 750$ & 750 & 0.0016 & 0.0016 & 0.0001 \\
\hline $20 \mathrm{P} 750$ & 750 & 0.0033 & 0.0033 & 0.0003 \\
\hline $30 \mathrm{P} 750$ & 750 & 0.0049 & 0.0049 & 0.0005 \\
\hline
\end{tabular}

The reaction mixture was then left overnight under reflux condition afterwards transferred to a refrigerator at $5^{\circ} \mathrm{C}$ for $24 \mathrm{hrs}$. In order to remove the needle-like dicyclohexylurea crystals, the reaction media was passed from Whattman filter paper grade 2 (Whattman, New Jersey, USA). Water was added as a non-solvent to the filtrate and the product was removed by decantation. The precipitate was dissolved again in acetone and the same purification process was repeated for 2-3 times. The resulting polymer was dried in a forced-air convection oven at $70^{\circ} \mathrm{C}$ for $12 \mathrm{hrs}$. The product appeared as a white, brittle and acetone-soluble powder, which was collected from filter paper and stored at $-5^{\circ} \mathrm{C}$ in a desiccator for further use.

\subsection{Fourier Transform Infrared (FTIR) Spectroscopy}

Fourier transform infrared (FTIR) spectra $\left(4000-400 \mathrm{~cm}^{-1}\right)$ were acquired using an Equinox 55 spectrophotometer (Bruker, Germany) at $4 \mathrm{~cm}^{-1}$ resolution and 32 scans at room temperature. FTIR spectra of mPEGs were collected by applying the materials on $\mathrm{KBr}$ disks while they were in liquid or molten state. Grafted copolymers were mixed thoroughly in 1:70 ratios with $\mathrm{KBr}$ in a mortar and pestle and equal weights ( $\cong 212 \mathrm{mg}$ ) were used to prepare compressed disks. All measurements were made in transmittance mode.

\subsection{Proton Nuclear Magnetic Resonance Spectroscopy ( ${ }^{1}$ HNMR)}

Proton nuclear magnetic resonance spectra ( $\left.{ }^{1} \mathrm{HNMR}\right)$ of the purified copolymers were recorded using a Bruker UltraShield 400 system (Bruker, Germany) at $25^{\circ} \mathrm{C}$ to characterize the copolymer structure and confirm the inclusion of 
mPEG chains on MA-co-MMA backbone. Samples were dissolved in deuterated acetone and chemical shifts were recorded in ppm from the signal of tetramethylsilane.

\subsection{Grafting Efficiency}

Grafting efficiency (GE\%) was evaluated by determination of the unreacted carboxylic acid content of MA-co-MMA- $g$-mPEG by a titration technique as previously described in the section under determination of methacrylic acid content. Titrations were performed kinetically on $0.5,1,2$ and $4 \mathrm{hrs}$ after initiation of the grafting reaction i.e. complete addition of $\mathrm{mPEG}$ to the reaction flask. $\mathrm{GE}(\%)$ was calculated according to the following equation:

$$
G E(\%)=\frac{M A_{I}-M A_{G}}{M A_{I}} \times 100
$$

where, $\mathrm{MA}_{\mathrm{I}}$ and $\mathrm{MA}_{\mathrm{G}}$ represent to the methacrylic acid content of the initial and grafted copolymers, respectively.

\subsection{In vitro Cell Culture}

The mouse fibroblast connective tissue (L929) cell line (NCBI C-161, National Cell Bank of Iran, Pasteur Institute of Iran, Tehran, Iran) were cultured in RPMI-1640 (GIBCO, Scotland) supplemented with $10 \%$ fetal calf serum (FCS) (Seromed, Germany), $100 \mathrm{IU} / \mathrm{mL}$ penicillin and $100 \mu \mathrm{g} / \mathrm{mL}$ streptomycin (Sigma, Milwaukee, USA). L929 cells were then harvested with $0.25 \%$ trypsin-EDTA solution (Sigma, Milwaukee, USA) in phosphate-buffered saline (PBS, pH 7.4) and seeded onto the 96-well microtiter plates (NUNC, Denmark) at a density of $1 \times 10^{4}$ cells/well for direct contact tests. Tissue culture polystyrene (TCPS) was used as a reference to perfect cell culturing. The cells were incubated at $37^{\circ} \mathrm{C}$ in humified air with $5 \% \mathrm{CO} 2$ for one week.

\subsection{Statistical Analysis}

Statistical analysis was performed using MiniTab software (Release 11.12, Minitab Inc., State College, PA, USA). Data were reported as mean \pm standard deviation at significant level of $p<0.05$. Outliers were rejected from processing using the $T$ procedure. Differences between groups were analyzed using one-way analysis of variance (ANOVA) and considered statistically significant when the $p$ value was less than 0.05 .

\section{Results and Discussion}

Using the previously described method in determination of acid value for MA-co-MMA copolymer, $28.02 \%$ methacrylic acid units (equivalent to $1.625 \mathrm{mmol} / \mathrm{g}$ based on dry polymer weight) was present in the polymer composition. Three levels of mPEG concentration, in feed, were considered for grafting i.e. 10,20 and $30 \%$ (molar ratio to methacrylic acid units) in order to provide various copolymers of different hydrophilic characteristics. The effect of varying molecular weight of the hydrophilic units (mPEG) on the hydrophilic nature of copolymers was previously shown by Hashemi Doulabi et al.[44]. Grafted copolymers were synthesized by adopting a direct condensation procedure based on the employment of an esterification promoting agent i.e. DCC. According to the supposed reaction mechanism for Steglich esterification i.e. the production of the ester bonds in the presence of DCC and DMAP[45], carboxylic acid functional groups present in MA-co-MMA copolymer were converted to an O-acylisourea intermediate upon reaction with DCC, which offers reactivity similar to the corresponding carboxylic acid anhydride functional groups. This reactive intermediate then forms an acyl pyridinium species with DMAP (I), followed by equilibration of (I) with the mPEG to produce ion pair (II). Upon recovery of the DMAP, grafted copolymer and stable dicyclohexylurea (DHU) byproduct were generated via nucleophilic attack by $\mathrm{R}^{\prime} \mathrm{O}-$ on the acyl group of (II) to provide a terpolymer of methyl methacrylate, methacrylic acid and monomethyl polyethylene glycol methacrylate. The reaction mechanism is illustrated in Figure 1.
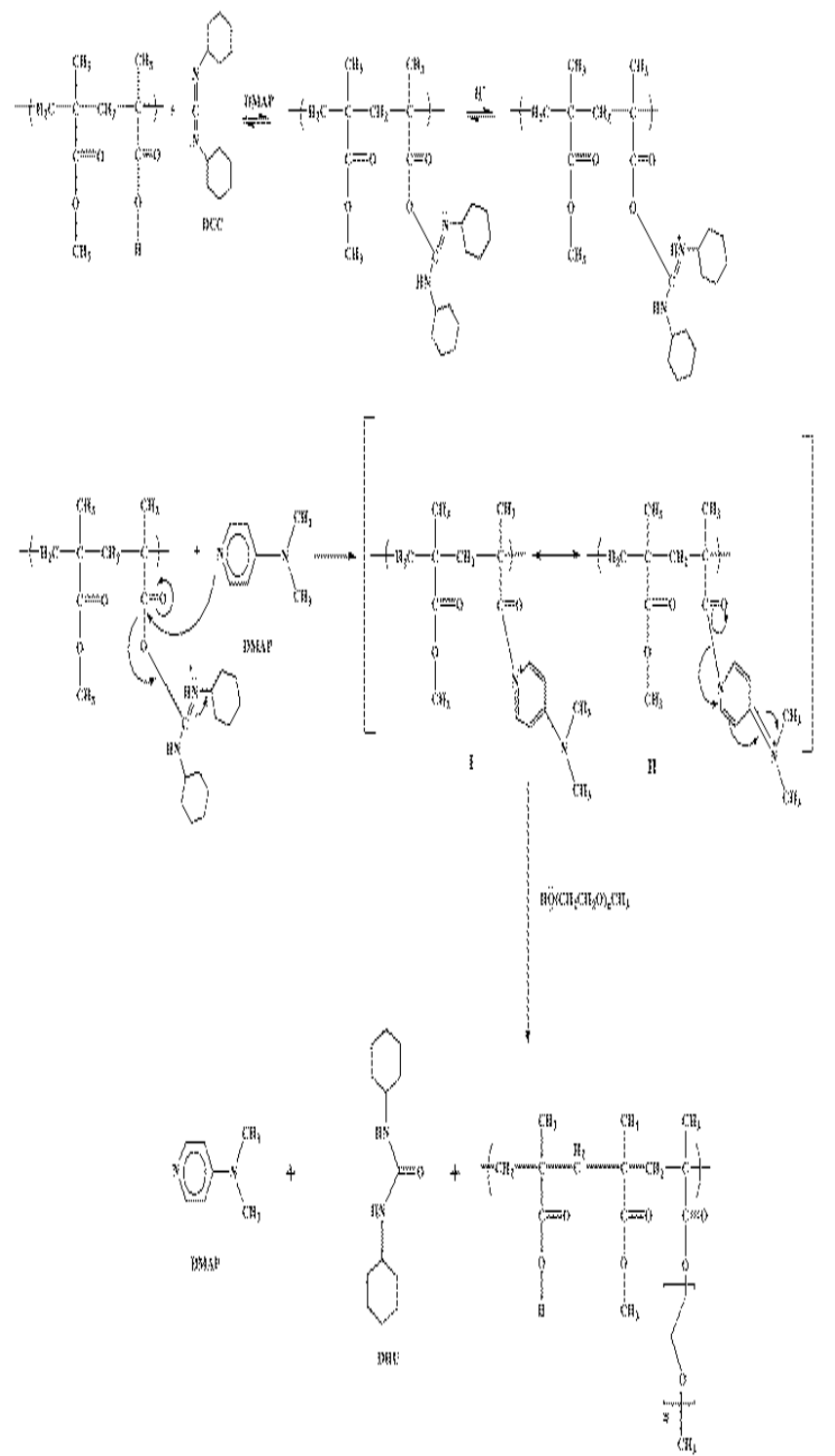

Figure 1. The Proposed Scheme for Grafting Reaction Mechanism. 
FTIR spectra of the initial MA-co-MMA copolymer along with polyethylene glycol mono methyl ether- $g$-poly (methacrylic acid-co-methyl methacrylate) in different molar ratio and $\mathrm{mPEG}$ nominal molecular weights are shown in Figure 2.

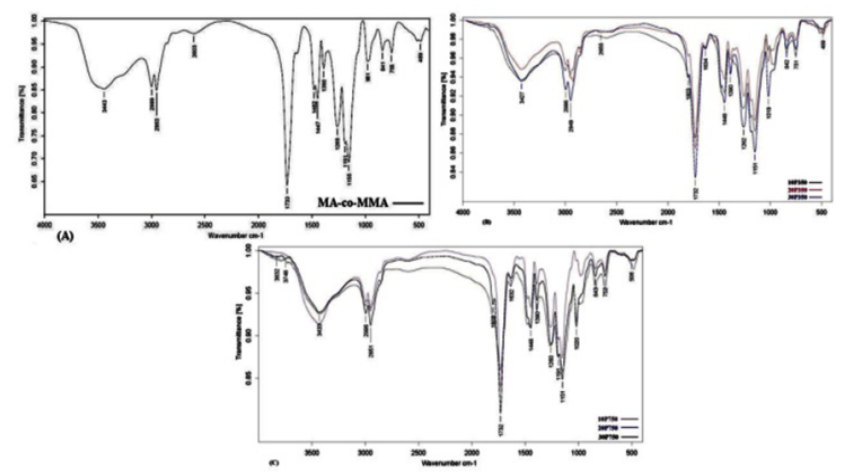

Figure 2. FTIR Spectra of the Initial MA-co-MMA Copolymer (A) and Grafted Copolymer Using Mpeg of 350 (B) And 750 g.mol ${ }^{-1}$ (C) Nominal Molecular Weights in $10(\longrightarrow, 20(\longrightarrow)$ and $30 \%(-)$ Feed Ratio.

FTIR spectra of the initial MA-co-MMA copolymer revealed the specific signals related to hydroxyl $\left(3443 \mathrm{~cm}^{-1}\right)$, methylene (2999 and $\left.2953 \mathrm{~cm}^{-1}\right)$, carbonyl $\left(1732 \mathrm{~cm}^{-1}\right)$ and alkyl-substituted ether $\left(1155 \mathrm{~cm}^{-1}\right)$ functional groups[46] which were declined in the finally grafted material's spectra, whereas performance of the esterification reaction was guaranteed by the appearance of new methoxy and methyl ether band signals at 2853 and $1020 \mathrm{~cm}^{-1}$, respectively.

Proton nuclear magnetic resonance ( ${ }^{1}$ HNMR) spectroscopy was used to confirm FTIR results. Appearance of mPEG ethoxy protons signal at $1.2 \mathrm{ppm}$ chemical shift clearly indicated the promotion of esterification reaction between MA-co-MMA and mPEG as shown in Figure 3a. Assignment of signals appeared in ${ }^{1} \mathrm{HNMR}$ spectra of starting materials and $\mathrm{mPEG}$-grafted copolymer are as follows:

${ }^{1} \mathrm{HNMR}: \delta 3.58$ (methoxy protons of MMA), $\delta 2.80$ (methylene functional group of mPEG adjacent to the formed carboxyl ester), $\delta 2.25$ (methyl functional group of MMA repeating units), $\delta 2.09\left(\mathrm{CH}_{3}\right.$ of deuterated acetone solvent signal), $\delta 1.87$ (methylene protons in mPEG backbone), $\delta 1.28$ (methylene protons on MA-co-MMA backbone), $\delta 1.2$ (ethoxy protons of mPEG), $\delta 0.88$ (methyl protons of MA-co-MMA side chains). The ratio of integrals for signal appeared at $2.8 \mathrm{ppm}$ to any signal originated by copolymer backbone can be correlated to the degree of grafting. The ${ }^{1} \mathrm{HNMR}$ spectra of MA-co-MMA and mPEG-grafted copolymers are depicted in Figure $3 \mathrm{~b}$.

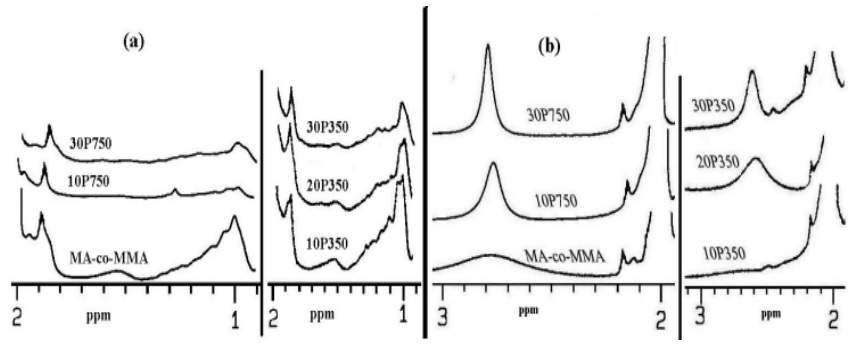

Figure 3. ${ }^{1} \mathrm{HNMR}$ Spectra of MA-co-MMA Along With the Corresponding
Grafted Materials.

Grafting efficiency (GE) was measured to assure the performance of the grafting reaction. GE was enhanced upon increasing in the $\mathrm{mPEG}$ percentage in the feed for a constant molecular weight (see Figure 4). This can be attributed to the well-known mass effect law; however, GE was reduced upon increasing in the molecular weight of mPEG in the feed, which can be attributed to the lower reactivity ratios of hydroxyl functional groups for higher molecular weight analogues of mPEG. The observed reduction in the GE upon increasing in the molecular weights of mPEG may also be assigned to the increasing potential of intra-molecular hydrogen bond formation between the polyacid and polyol i.e. $\mathrm{mPEG}$ chains. The reaction time usually plays an important role in a condensation reaction but in this specific case the grafting was nearly completed after first hour hence, no statistically significant differences $(p>0.5)$ was observed after that.

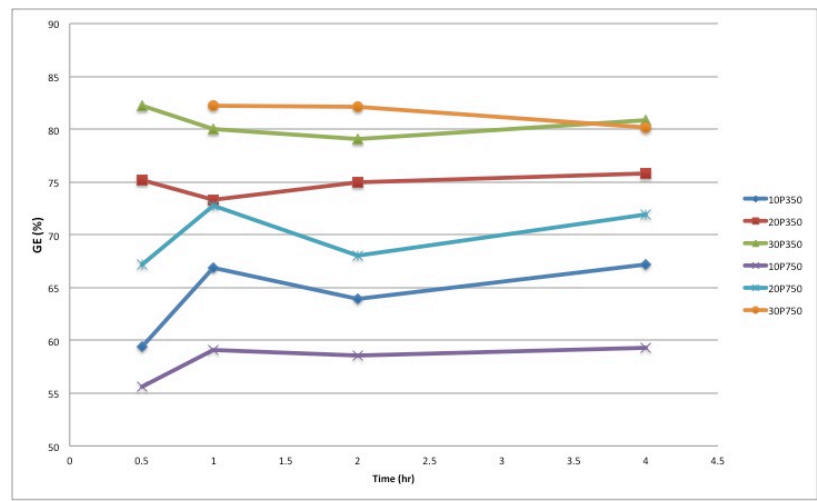

Figure 4. Grafting Efficiency for Different Compositions Versus Reaction Time.

Cytotoxicity evaluation of the grafted copolymers using L929 fibroblast cell line elucidated acceptable biocompatibility profile also applicability of the copolymers in biomedical field. Direct observation of cells in the close proximity of the PEG-grafted samples revealed that a considerable amount of cells on the copolymers who were started spreading and obtaining their fibroblastic morphology. Morphology of L929 cells for 20P750 sample after one-week incubation in the presence of polymeric sample is illustrated in Figure 5 in comparison to control group (TCPS).

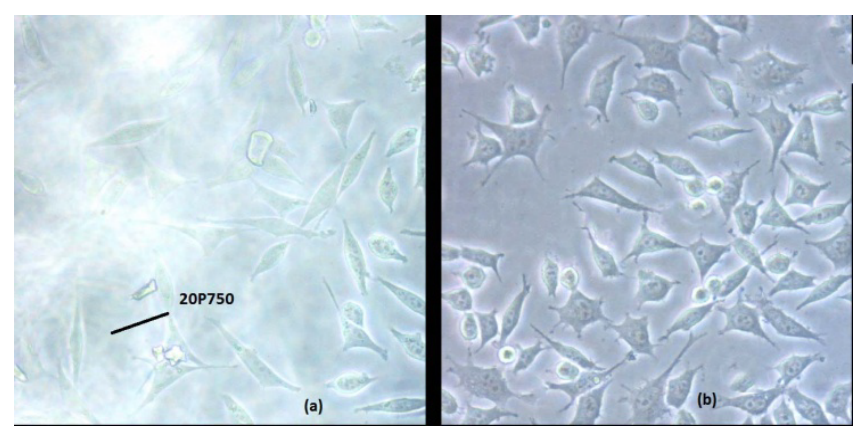

Figure 5. Cell Morphology of L929 Fibroblasts After Seven Days Culturing on (A) TCPS Plate and (B) 20P750 Copolymer.

Exposed surface areas of the cells were obtained via image 
analysis using Image-pro plus software. Data were collected for at least 6000 cells in each sample and the test was run in quadricate. As it is evident from data represented in Table 2, cells were got more flattened upon introduction of $\mathrm{mPEG}$ into the structure of copolymer $(p<0.05)$, however, there were no statistically significant difference between 10, 20 and $30 \% \mathrm{mPEG}$ grafted samples $(p>0.5)$. According to the results significant changes will be occurred by incorporation a limited amount of $\mathrm{mPEG}$ in the structure of the grafted copolymer $(10 \% \mathrm{mPEG})$ but incorporation of these higher ratios of hydrophilic moieties will not end to better results.

Table 2. Surface Area of L929 Fibroblasts Cultured on PEG Grafted Copolymer Samples After Two Weeks Exposure

\begin{tabular}{|c|c|}
\hline Sample & Cell Area (pixel) \\
\hline TCPS & $15.10 \pm 5.06$ \\
\hline $10 \mathrm{P} 750$ & $42.99 \pm 19.26$ \\
\hline $20 \mathrm{P} 750$ & $56.57 \pm 11.52$ \\
\hline $30 \mathrm{P} 750$ & $69.84 \pm 48.88$ \\
\hline
\end{tabular}

\section{Conclusions}

The terpolymer of methyl methacrylate, methacrylic acid and monomethoxy polyethylene glycol was synthesized by direct condensation reaction of $\mathrm{MPEG}$ and MA-co-MMA via Steglich mechanism using DCC as an esterification-promoting agent in the presence of DMAP. Chemical structure of the resulting materials were characterized spectroscopically by FTIR and ${ }^{1}$ HNMR techniques which clearly confirmed the significant changes upon grafting reaction including the appearance of carbonyl ester signal band absorption in FTIR also chemical shift at $2.8 \mathrm{ppm}$ in ${ }^{1} \mathrm{HNMR}$ spectroscopy which can be assigned to the methylene groups of mPEG just adjacent to carbonyl functional groups of MA upon the reaction. GE was dependent on the initial $\mathrm{mPEG}$ molecular weights and its concentration in the feed ratio but no significant changes were observed after one hour due to the rapid progression of the reaction at first times. Moreover, seven days in vitro cytotoxicity examination to evaluate cellular proliferation in the neighborhood of the grafted copolymer was in good agreement with the control groups showing higher biocompatibility profile for samples grafted with $10 \%$ of mPEG in comparison to neat ones. Increasing mPEG content to higher values did not improve the results further on.

\section{ACKNOWLEDGMENTS}

The authors express their sincere gratitude to Iran Polymer and Petrochemical Institute for providing financial support to this research (contract grant number: 23711113). Providing MA-co-MMA copolymer by Röhm Pharma GmbH is highly appreciated.

\section{REFERENCES}

[1] Shafranska O, Kokott A, Sulthaus D, Ziegler G, Effect of surface modification of polymer beads on the mechanical properties of acrylic bone cement. J Biomater Sci Polym Ed 2007; 18: 439-451, doi:10.1163/156856207780425040

[2] Behniafar H, Haghighat S, Farzaneh S, Direct synthesis of soluble and thermally stable poly(urethane-imide)s from a new triimide-dicarbonylazide. Polymer 2005; 46: 4627-4634, doi:10.1016/j.polymer.2005.03.067

[3] Balakrishnan B, Kumar DS, Yoshida Y, Jayakrishnan A, Chemical modification of poly(vinyl chloride) resin using poly(ethylene glycol) to improve blood compatibility. Biomaterials 2005; 26: 3495-3502,

doi:10.1016/j.biomaterials.2004.09.032

[4] Goddard J M, Hotchkiss JH, Polymer surface modification for the attachment of bioactive compounds. Prog Polym Sci 2007; 32: 698-725, doi:10.1016/j.progpolymsci.2007.04.002

[5] Ma Z, Mao Z, Gao C, Surface modification and property analysis of biomedical polymers used for tissue engineering. Colloid Surface B 2007; 60: 137-157, doi:10.1016/j.colsurfb.2007.06.019

[6] Wang P, Tan KL, Kang ET, Surface modification of poly (tetrafluoroethylene) films via grafting of poly(ethylene glycol) for reduction in protein adsorption. J Biomater Sci Polym Ed 2000; 11(2): 169-186, doi:10.1163/156856200743634

[7] Laia JY, Hsiuec GH, Functional biomedical polymers for corneal regenerative medicine. React Funct Polym 2007; 67: 1284-1291, doi:10.1016/j.reactfunctpolym.2007.07.060

[8] Chen H, Yuan L, Song W, Wu Z, Li D, Biocompatible polymer materials: Role of protein-surface interactions. Prog Polym Sci 2008; 33: 1059-1087,

doi:10.1016/j.progpolymsci.2008.07.006

[9] Chu PK, Chen JY, Wang LP, Huang N, Plasma surface modification of biomaterials. Mater Sci Eng 2002; 36: 143-206, doi:10.1016/S0927-796X(02)00004-9

[10] Pappas D, Bujanda A, Demaree JD, Hirvonen JK, Kosik W, Jensen R, et al. Surface modification of polyamide fibers and films using atmospheric plasmas. Surf Coat Tech 2006; 201: 4384-4388, doi:10.1016/j.surfcoat.2006.08.068

[11] Tusek L, Nitschke M, Werner C, Stana-Kleinschek K, Ribitsch V, Surface characterization of $\mathrm{NH}_{3}$ plasma treated polyamide 6 foils. Colloid Surface A 2001; 195: 81-95, doi:10.1016/S0927-7757(01)00831-7

[12] Wei QF, Gao WD, Hou DY, Wang XQ, Surface modification of polymer nanofibres by plasma treatment. Appl Surf Sci 2005; 245: 16-20, doi:10.1016/j.apsusc.2004.10.013

[13] Errifai I, Jama C, Le Bras M, Delobel R, Gengembre L, Mazzah A, et al. Elaboration of a fire retardant coating for polyamide- 6 using cold plasma polymerization of a fluorinated acrylate. Surf Coat Tech 2004; 180-181: 297-301, doi:10.1016/j.surfcoat.2003.10.074

[14] Dumitrascu N, Borcia C, Borcia G, Control of the 
blood-polymer interface by plasma treatment. J Biomed Mater Res B 2008; 87: 364-373, doi:10.1002/jbm.b.31112

[15] Khorasani MT, Mirzadeh H, Irani S, Plasma surface modification of poly ( $L$-lactic acid) and poly (lactic-co-glycolic acid) films for improvement of nerve cells adhesion. Radiat Phys Chem 2008; 77: 280-287, doi:10.1016/j.radphyschem.2007.05.013

[16] Wang DA, Engineering Blood-Contact Biomaterials by "H-Bond Grafting" Surface Modification. Adv Polym Sci 2007; 209: 179-227, doi:10.1007/12_2006_107

[17] Bhattacharyaa A, Misrab BN, Grafting: a versatile means to modify polymers techniques, factors and applications. Prog Polym Sci 2004; 29: 767-814, doi:10.1016/j.progpolymsci.2004.05.002

[18] Uyama Y, Kato K, Ikada Y, Surface modification of polymers by grafting. Adv Polym Sci 1998; 137: 1-39, doi:10.1007/3-540-69685-7_1

[19] Shung AK, Behravesh E, Jo S, Mikos AG, Crosslinking characteristics of and cell adhesion to an injectable poly (propylene fumarate-co-ethylene glycol) hydrogel using a water-soluble crosslinking system. Tissue Eng 2003; 9: 243-254, doi:10.1089/107632703764664710

[20] Taguet A, Ameduri B, Boutevin B, Crosslinking of vinylidene fluoride-containing fluoropolymers. Adv Polym Sci 2005; 184: 127-211, doi:10.1007/b136245

[21] Kadłubowski S, Henke A, Ulański P, Rosiak J, Bromberg A, Hatton TA, Hydrogels of polyvinylpyrrolidone (PVP) and poly (acrylic acid) (PAA) synthesized by photoinduced crosslinking of homopolymers. Polymer 2007; 48:4974-4981, doi:10.1016/j.polymer.2007.06.033

[22] Okpalugo TIT, Ogwu AA, Maguire PD, McLaughlin JAD, Platelet adhesion on silicon modified hydrogenated amorphous carbon films. Biomaterials 2004; 25: 239-245, doi:10.1016/S0142-9612(03)00494-0

[23] Bovicelli P, Antonioletti R, Onori A, Delogu G, Fabbri D, Dettori MA, Regioselective halogenation of biphenyls for preparation of valuable polyhydroxylated biphenyls and diquinones. Tetrahedron 2006; 62: 635-639, doi:10.1016/j.tet.2005.10.009

[24] Lime F, Irgum K, Hydrobromination of residual vinyl groups on divinylbenzene polymer particles followed by atom transfer radical surface graft polymerization. J Polym Sci A 2009; 47: 1259-1265, doi:10.1002/pola.23209

[25] Christie WW, Preparation of ester derivatives of fatty acids for chromatographic analysis. In: Christie WW, Ed. Advances in lipid methodology. Bridgwater: PJ Barnes \& Associates, 1993: 69-111

[26] Hinds KD, Protein conjugation, cross-linking, and pegylation. In: Mahato RI, Ed. biomaterials for delivery and targeting of proteins and nucleic acids. New York: CRC Press, 2005: $120-187$

[27] Chapman AP, PEGylated antibodies and antibody fragments for improved therapy: a review. Adv Drug Deliver Rev 2002; 54: 531-545, doi:10.1016/S0169-409X(02)00026-1

[28] Pfeifer BA, Burdick JA, Langer R, Formulation and surface modification of poly(ester-anhydride) micro- and nanospheres. Biomaterials 2005; 26: 117-124, doi:10.1016/j.biomaterials.2004.02.015

[29] Asatekin A, Kang S, Elimelech M, Mayes AM, Anti-fouling ultrafiltration membranes containing polyacrylonitrile-graftpoly(ethylene oxide) comb copolymer additives. J Membrane Sci 2007; 298: 136-146, doi:10.1016/j.memsci.2007.04.011

[30] Peppas NA, Klier J, Controlled release by using poly (methacrylic acid-g-ethylene glycol) hydrogels. J Control Release 1991; 16: 203-214, doi:10.1016/0168-3659(91)90044-E

[31] Ahn JS, Choi HK, Cho CS, A novel mucoadhesive polymer prepared by template polymerization of acrylic acid in the presence of chitosan. Biomaterials 2001; 22: 923-928, doi:10.1016/S0142-9612(00)00256-8

[32] Foss AC, Goto T, Morishita M, Peppas NA, Development of acrylic-based copolymers for oral insulin delivery. Eur $\mathrm{J}$ Pharm Biopharm 2004; 57: 163-169, doi:10.1016/S0939-6411(03)00145-0

[33] Serra L, Domenech J, Peppas NA, Drug transport mechanisms and release kinetics from molecularly designed poly (acrylic acid-g-ethylene glycol) hydrogels. Biomaterials 2006; 27: 5440-5451, doi:10.1016/j.biomaterials.2006.06.011

[34] Chiu HC, Hu CH, Chern CS, Preparation and characterization of amphiphilic poly(ethylene glycol) graft copolymers. Polymer J 1999; 31: 535-541, doi:10.1295/polymj.31.535

[35] Chiu HC, Chern CS, Lee CK, Chang HF, Synthesis and characterization of amphiphilic poly(ethylene glycol) graft copolymers and their potential application as drug carriers. Polymer 1998; 39: 1609-1616, doi:10.1016/S0032-3861(97)00436-9

[36] Lee JH, Kopeckova P, Kopecek J, Andrade JD, Surface properties of copolymers of alkyl methacrylates with methoxy(polyethylene oxide) methacrylates and their applications as protein-resistant coatings. Biomaterials 1990; 11: 455-464, doi:10.1016/0142-9612(90)90058-X

[37] Bo G, Wesslen B, Wesslen KB, Amphiphilic comb-shaped polymers from poly(ethylene glycol) macromonomers. J Polym Sci A 1992; 30: 1799-1808, doi:10.1002/pola.1992.080300903

[38] Wesslen B, Wesslen KB, Preparation and properties of some water-soluble, comb-shaped, amphiphilic polymers. J Polym Sci A 1989; 27: 3915-3926, doi:10.1002/pola.1989.080271204

[39] Atta AM, Arndt KF, Synthesis and characterization of anionic graft copolymers containing poly(ethylene oxide) grafts. J App Polym Sci 2002; 86: 1138-1148, doi:10.1002/app.11151

[40] Twaik MA, Tahan M, Zilkha A, Grafting of poly(ethylene oxide) on poly(methyl methacrylate) by transesterification. J Polym Sci A 1969; 7: 2469-2480, doi:10.1002/pol.1969.150070901

[41] Thierry A, Skoulios A, Copolymeres greffes: Poly (methacrylate d'alkyl-g-oxyde d'ethylene), 1 . Synthese et caracterisation. Die Makromolekulare Chemie 1976; 177: 319-335, doi:10.1002/macp.1976.021770202

[42] Jannasch P, Wesslen B, Synthesis of poly(styrene- $g$ - ethylene oxide) by ethoxylation of amide group containing styrene copolymers. J Polym Sci A 1993; 31, 1519-1529, doi:10.1002/pola.1993.080310622 
[43] The United State Pharmacopeia XXV, The National Formulary XX, Rockville, Md., United States Pharmacopeial Convention, Inc., 2002: 2579-2580

[44] Doulabi ASH, Sharifi S, Imani M, Mirzadeh H, Synthesis and characterization of biodegradable in situ forming hydrogels via direct polycondensation of poly (ethylene glycol) and fumaric acid. Iran Polym J 2008; 17: 1-9
[45] Neises B, Steglich W, Esterification of carboxylic acids with dicyclohexylcarbodiimide/4-dimethylaminopyridine: tert-butyl ethyl fumarate. Org Synth 1990; 63: 183-186

[46] Rufino ES, Monteiro EEC, Infrared study on methyl methacrylate-methacrylic acid copolymers and their sodium salts. Polymer 2003; 44: 7189-7198, doi:10.1016/j.polymer.2003.08.041 